\title{
Profession scientist
}

One standard question on visa application forms is to ask the applicant for his or her profession. For years I have been writing 'scientist' in the appropriate space. But recently, I have wondered when that response first became true. Was it when I received my bachelor's degree? Or my $\mathrm{PhD}$ ? Or when I started my own research group? I have been trained to be a scientist for a very long time, and the reality is that this process never ends-so, perhaps, one never is a scientist! For those with a degree in engineering, pharmacy or medicine, such a question does not arise. They have a professional structure and a validating body that, at a certain point in their career, accepts them as members of that structure by following a set of well-established rules. Scientists do not have such a structure, nor even the semblance of one. Even the committees that award degrees abide by rules that vary not only between different countries, but from university to university.

I recall an evening when I was speaking to parents and young people about career choices. I was the scientist on the panel and was there to explain why science is a great career choice for those who are interested. One father came to me after the presentation and said, 'if my daughter does a science degree, what will she become?' He could not fit a scientist into any job description. Indeed, like an arts degree, a science degree prepares you only for the next phase of your life. It is not an end point, the definition of which is equally complex. As an undergraduate, it is unreal to think that you are making the first strides towards becoming a full professor. It is merely possible to see the next step up the ladder, i.e. a $\mathrm{PhD}$, as an achievable goal. When the $\mathrm{PhD}$ is in sight, it is acceptable to say that a postdoctoral position is the next rung on your career ladder. And so it continues until you reach the point where you are at last in control of your own fate and can see a predictable future on the horizon. In my case, that feeling came about four years after my PhD. In other words, it took 11 years of working long days and weekends to 'get there'. When it happened, a friend told me that a barman with no qualifications earned more than I did. For some of us, this is not relevant because our work satisfies us more than working behind a bar ever could. However, it is difficult to make the job of a scientist attractive to those at the point of making an initial career choice if the map for the journey ahead reads: (i) difficult studies for 3-4 years with no financial support; (ii) a further 4 years with increasing challenges and uncertainties and a very low level of income; (iii) applying for a fellowship to work in a good laboratory in a good location-but only if you are amongst the best and can still afford to continue from a social and financial point of view. Finally, at some undetermined point in the future, your apprenticeship will be judged by others and you will be able to compete for a real job. This position will probably be poorly paid and may not match either your interest or your desired location, and you may spend many years trying to improve these aspects. In the meantime, you face a continuing challenge to find funding, time and people to do the research, which, after all, is the basis by which you are judged.

And if you tell someone outside the world of science that you are a scientist, the reaction will be a mix of confrontation and bemusement, because not everybody understands what you do and because scientists are blamed for many negative aspects of technology. This is the underpaid, insecure and unappreciated career to which we are trying to attract young people. And we are surprised that they are reticent!

Many aspects of this scenario must be changed. There are demographic trends that show an ageing population; thus, positions at all levels in the training and delivery of scientific endeavour will need to be filled. Industries in the developed world are moving from standard manufacturing to high-tech processes, and need a large number of trained scientists. The impact of science on our daily lives will grow and a rupture between those that are scientifically literate and those that are scared of its consequences will be disastrous. We need to train politicians, teachers, public servants and journalists to ensure that the benefits of science are understood and that the risks of novel developments can be judged reasonably.

Therefore, it is clear that we must take measures now to ensure that there are people at all layers of society trained in science. This obviously does not mean that all students need to aim at a professorship. It does mean that those who turn away from that particular path to practice their science in a different way should still be valued by their former colleagues and by society. They have not failed. They too, should be able to say they are scientists. They are an addition to the answer for those who wonder what they will become if they start on the road to a science degree. Scientists in general should be rewarded in line with their increasing importance in economic and social wellbeing. And we should establish a system to ensure that the label 'scientist' is defined, recognised and sought after.

\section{Frank Gannon}

DOI: 10.1093/embo-reports/kvf015 